\title{
Socio-demographic Characteristics of Drug Abusers Attending a De-addiction Center in Dhaka \\ Kabir $\mathrm{SMH}^{1}$, Shaikh MAK${ }^{2}$, Ahmed $\mathrm{M}^{3}$, Begum $\mathrm{M}^{4}$, Zafreen $\mathrm{F}^{5}$, Mazumder $\mathrm{AH}^{6}$ \\ DOI: https://doi.org/10.3329/jafmc.v14i2.45887
}

\begin{abstract}
Introduction: Drug addiction is a social curse involving all classes of people for ages. Not only it increases individuals morbidity and mortality but also creates social unrest and reduces the national productivity frequent assessment surveys have provided insights into the pattern and required responses.
\end{abstract}

Objectives: To assess the sociodemographic profile of drug addicts admitted in a prominent drugs deaddiction centre of Dhaka, Bangladesh.

Materials and Methods: This cross-sectional descriptive study carried out on 158 admitted patients in Thikana Psychiatric/ Drug de-addiction clinic, from October 2014 to September 2015. A predesigned questionnaire used in evaluating the patients by two or more sittings face-to-face interviews.

Results: Amongst 158 patients, $94.30 \%$ were male and $62.0 \%$ were in the age group of 21-30 years with a mean age of $26.46+$ 6.168 years. Majority (60.8\%) patients were married and $48.7 \%$ had education up to higher secondary level, $29.1 \%$ were unemployed and $27.2 \%$ students. About $36.7 \%$ were spending between 101 500 Taka/day and $65.8 \%$ arrange money for drugs by themselves. The reason behind starting drug abuse was mainly peer pressure (49.4\%) followed by curiosity (26.6\%). The mean age of starting drug was $19.42+7.68$ years and $68.35 \%$ were addicted to the drug for the period between $1-5$ years. Only $4.4 \%$ had positive family history of drug abuse. Regarding route of drug abuse, ingestion was most popular (55.1\%) and only $8.9 \%$ participants were using injectable route. Amongst abused drugs, Amphetamine (Yaba) was most popular among the female $(77.7 \%)$ and students $(21.5 \%)$.

Conclusion: Drug abuse cripples the individual, the family, the society and finally the nation. Since younger generations most affected by the drug abuse, it is prudent to evolve and apply preventive, curative and rehabilitative strategies before it is too late.

Key-words: Socio-demographic profile, Drugs abusers, Amphetamine.

\section{Introduction}

Drug addiction or substance abuse is a chronic, often relapsing brain disease that causes compulsive drug seeking and use despite harmful consequences to the individual who is addicted and to those around them 1 . Although the history of substance abuse is as old as mankind, recently it has become a global problem that is influenced by social, economic, political and psychological factors ${ }^{2}$. The problem is not merely that of an individual or a community and a drug but involves interactive between triad. As hemmed between the largest opium-producing zone 'Golden Triangle' and 'Golden Crescent', Bangladesh is a natural transit zone of drugs ${ }^{3}$. However, with socioeconomic development over the past few decades, the drug abuse scenario in the region has changed rapidly and the changes observed in terms of availability, choice of psychoactive drugs, users and their socio-demographic characteristic ${ }^{4}$. As of 2013 statistics, there were six million drug users were in Bangladesh and every day this number is rising in alarming speed irrespective of class or region ${ }^{5}$. This study aims to assess the sociodemographic profile of drug addicts admitted in a prominent drugs deaddiction centre of Dhaka, Bangladesh.

\section{Materials and Methods}

This cross-sectional descriptive study carried out in a private drug de-addiction hospital 'Thikana' located at Dhaka city from October 2014 to September 2015. Total 158 substance users, admitted in the hospital were included in the study after obtaining consent from the patients in cases of adults and from parents in cases of minors. Patients who were mentally retarded, intoxicated, seriously ill or unwilling to participate in the study excluded. Two or more sitting carried out to build a rapport and confidence amongst the patients that helped in extracting more information. A predesigned and pretested questionnaire used in evaluating the patients and the collected data were analyzed by SPSS 17.0 for Windows.

\section{Results}

Total 158 patients were included in this study amongst them 149 were male $(94.3 \%)$ and $9(5.7 \%)$ were female. The mean age of the patients was $26.46+6.168$ years, with a range of $16-59$ years. Majority $(62.0 \%)$ patients were in the age group of 21-30 year followed by $31-40$ years $(29.7 \%)$. Regarding religion 146 patients (92.4\%) were Muslim and Ten (6.3\%) were Hindu. Most of the patients studied (60.8\%) were married,

\footnotetext{
1. Brig Gen SM Humayun Kabir, MBBS, MPH, MPhil, Director, Chattogram Medical College Hospital, Chattogram (E-mail: smhumayun@ gmail.com) 2. Maj Muhammad Abdul Kayum Shaikh, MBBS, MCPS, FCPS, Classified Specialist in Psychiatry, Combined Military Hospital Cumilla 3. Col Masud Ahmed, MBBS, FCPS, Classified Specialist in Anaesthesiology, Combined Military Hospital, Cumilla 4. Dr Masuda Begum, BDS, DDS, Assistant Professor and Head, Department of Oral Anatomy and Physiology, Marks Medical College (Dental Unit), Mirpur-14, Dhaka 5. Dr Farzana Zafreen, MBBS, MPH, Associate Professor and Head, Department of Community Medicine, Medical College for Women \& Hospital, Uttara, Dhaka. 6. Dr Atiqul Haq Mazumder, MBBS, MD, Assistant Professor, National Institute of Mental Health and Hospital, Dhaka.
} 
56 patients (35.4\%) were unmarried whereas $06(3.8 \%)$ were separated or divorced. Most of the patients (48.7\%) had education up to higher secondary level followed by graduation or more $33(20.9 \%)$. Regarding occupation $46(29.1 \%)$ were unemployed and students $43(27.2 \%)$. Monthly family income of the patient or their family was worthy in between 1500030,000 Taka 60(38.6\%) followed by 5000-15000 Tk 38(24.1\%) (Table-I). Majority of the patients 58(36.7\%) were spending 101-500 Taka/day followed by <50 Taka/day by $41(25.9 \%)$ and 51-100 Tk/day 39(24.7\%). To arrange money for purchasing drugs 104(65.8\%) were dependent on self, $17(10.8 \%)$ were dependent on family and 28 patients $(17.7 \%)$ were involved in some sorts of crime like thief or hijacking. The reasons behind starting drug abuse mainly were peer-pressure $78(49.4 \%)$ followed by curiosity $42(26.6 \%)$ and frustration due to unemployment $18(11.4 \%)$, familial disharmony $12(7.6 \%)$ or failure in love $8(5.1 \%)$. Most of the patients $108(68.4 \%)$ were addicted for the period between 1-5 years followed by between $5-10$ years $39(24.7 \%)$ and the mean age of starting drug was $19.4+7.68$ years. Only seven patients $(4.4 \%)$ had positive family history of drug abuse. Regarding route of drug abuse, ingestion was the most popular $86(55.1 \%)$ followed by multiple routes $34(21.5 \%)$, inhalation $24(14.6 \%)$ and only 17 patients $(10.7 \%)$ were using injectable route. Highest 34 $(21.5 \%)$ were addicted to tablet Yaba (amphetamine) and multiple substances, followed by Cannabis $24(14.6 \%)$ and phencyclidine 22(13.9\%) were next popular amongst addicts. Only $15(9.5 \%)$ were admitted with sedative addiction and 14 $(8.9 \%)$ because of pethidine addiction (Table-II).

Table-I: Socio-demographic status of the patients $(n=158)$

\begin{tabular}{|c|c|c|c|}
\hline \multicolumn{2}{|c|}{ Variables } & $\begin{array}{c}\text { No of } \\
\text { Patients }\end{array}$ & $\begin{array}{c}\text { Percentage } \\
(\%)\end{array}$ \\
\hline \multirow{6}{*}{ Age ( in years) } & $16-20$ & 07 & 4.4 \\
\hline & $21-30$ & 98 & 62.0 \\
\hline & $31-40$ & 47 & 29.7 \\
\hline & \begin{tabular}{|l}
$11-50$ \\
41
\end{tabular} & 05 & 3.2 \\
\hline & $>50$ & 01 & 0.6 \\
\hline & \multicolumn{3}{|c|}{ Mean \pm SD $26.46 \pm 6.168$} \\
\hline \multirow[b]{2}{*}{ Sex } & Male & 149 & 94.3 \\
\hline & Female & 09 & 5.7 \\
\hline \multirow{3}{*}{ Religion } & Muslim & 146 & 92.4 \\
\hline & \begin{tabular}{|l|} 
Hindu \\
\end{tabular} & 10 & 6.3 \\
\hline & Christian & 02 & 1.26 \\
\hline \multirow{3}{*}{ Marital Status } & Unmarried & 56 & 35.4 \\
\hline & Married & 96 & 60.8 \\
\hline & Separated & 06 & 3.8 \\
\hline \multirow{5}{*}{ Educational Status } & \begin{tabular}{|l|l|} 
Illiterate \\
\end{tabular} & 08 & 5.1 \\
\hline & Primary & 11 & 7.0 \\
\hline & Secondary & 29 & 18.4 \\
\hline & Higher Secondary & 77 & 48.7 \\
\hline & Graduation or More & 33 & 20.9 \\
\hline \multirow{5}{*}{ Occupation } & Student & 43 & 27.2 \\
\hline & Employed & 22 & 13.9 \\
\hline & Unemployed & 46 & 29.1 \\
\hline & Business & 36 & 22.8 \\
\hline & Others & 11 & 6.96 \\
\hline \multirow{5}{*}{ Monthly Family Income (Taka) } & $<5000$ & 18 & 11.4 \\
\hline & $5001-15,000$ & 39 & 24.7 \\
\hline & \begin{tabular}{|l|}
$15,001-30,000$ \\
\end{tabular} & 61 & 38.6 \\
\hline & $30.001-50,000$ & 21 & 13.3 \\
\hline & $>50,000$ & 20 & 12.7 \\
\hline
\end{tabular}
information $(n=158)$

\begin{tabular}{|c|c|c|c|}
\hline \multicolumn{2}{|c|}{ Variables } & \multirow{2}{*}{\begin{tabular}{|c|} 
No of \\
Patients
\end{tabular}} & \multirow{2}{*}{\begin{tabular}{|c} 
Percentage \\
25.9
\end{tabular}} \\
\hline \multirow{5}{*}{$\begin{array}{l}\text { Amount spent per day } \\
\text { (Taka) }\end{array}$} & $<50$ & & \\
\hline & $50-100$ & 39 & 24.7 \\
\hline & $101-500$ & 58 & 36.7 \\
\hline & $501-1000$ & 16 & 10.1 \\
\hline & $>1000$ & 04 & 2.5 \\
\hline \multirow{4}{*}{$\begin{array}{l}\text { Source of money to } \\
\text { purchase drugs }\end{array}$} & Self & 104 & 65.8 \\
\hline & Family & 17 & 10.8 \\
\hline & Friends & 09 & 5.7 \\
\hline & Thief & 28 & 17.7 \\
\hline \multirow{5}{*}{ Reasons for starting drug } & Peer pressure & 78 & 49.4 \\
\hline & \begin{tabular}{|l|} 
Curiosity \\
\end{tabular} & 42 & 26.6 \\
\hline & Unemployment & 18 & 11.4 \\
\hline & Familial disharmony & 12 & 7.6 \\
\hline & Failure in love & 08 & 5.1 \\
\hline \multirow{4}{*}{ Duration of drug abuse } & $<5$ & 108 & 68.4 \\
\hline & $5-10$ & 39 & 24.7 \\
\hline & $>10-15$ & 10 & 6.3 \\
\hline & $>15$ & 01 & 0.6 \\
\hline Mean age of starting drug & \multicolumn{3}{|c|}{$19.4+7.68$ years } \\
\hline \multirow{2}{*}{$\begin{array}{l}\text { Family history of drug } \\
\text { abuse }\end{array}$} & Yes & 07 & 4.4 \\
\hline & No & 151 & 95.6 \\
\hline \multirow{4}{*}{ Route of drug abuse } & Ingestion & 86 & 55.1 \\
\hline & Inhalation & 23 & 14.6 \\
\hline & Injection & 14 & 8.9 \\
\hline & Multiple & 34 & 21.5 \\
\hline \multirow{8}{*}{ Type of drug abused } & Sedatives & 15 & 9.5 \\
\hline & Phencyclidinel & 22 & 13.9 \\
\hline & Cannabis & 23 & 14.6 \\
\hline & Heroin & 07 & 4.4 \\
\hline & Pethidine & 14 & 8.9 \\
\hline & Alcohol & 09 & 5.7 \\
\hline & \begin{tabular}{|l|} 
Amphetamine \\
\end{tabular} & 34 & 21.5 \\
\hline & \begin{tabular}{|l|} 
Multiple \\
\end{tabular} & 34 & 21.5 \\
\hline
\end{tabular}

\section{Discussion}

In this study, participants were predominantly male (94.3\%). This finding simulates with the findings of Lucy et al 4 who found it to be $96.1 \%$ whereas it was $100 \%$ male in the study carried out by Gupta VK et al ${ }^{5}$. This may be due to economic dependency of females on males and due to difficulty to procure the illegal drugs by themselves. A majority $(62.0 \%)$ of patients were in age group of 20-30 years as also found in other studies 6 . Most of the patients $(60.8 \%)$ in the study were married it might be more of the married patients take treatment for deaddiction may be due to motivation or pressure of family members. In this study, $48.7 \%$ patients had education of higher secondary level and $38.6 \%$ had monthly family income of 15000.00-30,000.00 Taka. This proportionately higher educational status and monthly income imply that these private hospitals are not affordable to patients of all classes of society or the rising trend of addiction in upper class. This contradicts the findings of study carried out in government hospital by Singh et al but consistent with the study by Gupta VK et al ${ }^{5}$.

Regarding reason to start drug abuse, peer pressure was responsible for $49.4 \%$ patient followed by curiosity $26.6 \%$, but Gupta VK et al ${ }^{5}$ found peer pressure to the causative factor in $79.2 \%$ patients whereas Desilva et al ${ }^{8}$ found that $74 \%$ initiated 
drugs as an experiment out of curiosity. Another study by Hossain et $a^{9}$ has found familial disharmony as major factor $(62.6 \%)$ for initiation of drug abuse. This difference could be because of researchers or patients' perception as most of the time peer pressure and curiosity overlaps. Mean age of starting drugs was $19.42+7.68$ years. Venkatesan and Stelina ${ }^{10}$ found that the number of people being initiated to substance abuse in early age 10 to 19 years and showed an increasing trend.

This study revealed about $55.1 \%$ were using the oral route and only $8.9 \%$ were using injectable route. This contradicts the findings of Islam SKN et al ${ }^{11}$ who found that injections to be the most popular $87 \%$ route. This difference may be changing pattern of drug availability and preference. Addicts on injectable drug are more vulnerable to communicable/infectious diseases like HIV, Hepatitis B, Hepatitis C abuse formation etc. Amongst the commonly abused drugs Yaba (methamphetamine) tablet predominates as it is easy to carry consume \& 'high' in feeling. Unlike the findings of Kadri et $\mathrm{al}^{12}$ who found alcohol is most commonly $(70.2 \%)$ abused drugs, it is only $5.70 \%$ in this study. This is because unlike India alcohol consumption is legally and religiously very restricted in Bangladesh. Peer pressure is the most important cause in starting substance abuse and most among the 21-30 years group (50\%), which indicates that most influential time of life by others. Amphetamine (Yaba) was the most likely substance among the addicts; easy availability might be the cause.

This cross-sectional study carried on patients who could afford relatively costly treatment of the de-addiction hospital of Dhaka. Therefore, along with limited number of study population this study could not cover the subjects of all corners of society or country. The sociodemographic profile of drug/ substance abusers varies from society to society country to country even time to time because of factors like economy, religion, rational policy social structure etc. The multiplicity of factors associated with drug abuse and their interrelatedness makes the problem a complex one ${ }^{13}$. Addicted patients from poor socioeconomic background usually remain unaccounted for and the failure of the nation and society to treat and reintegrate them into mainstream may prove disastrous in future.

\section{Conclusion}

Drug abuse cripples the individual, the family, the society and finally the nation. Since younger generations most affected by the drug abuse, it is prudent to evolve and apply preventive, curative and rehabilitative strategies before it is too late.
Support for which must come from all sides including families, educational institutions, community or social groups, law enforcing agency, policymakers and health professionals. Periodic survey of ever-changing sociodemographic pattern of drug addiction can guide the policymakers to help eradicate or control this social 'cancer'.

\section{References}

1. Ortiz A. Development of a systems for registry of information of drug use in Mexico. Bull Pan Am Health Orgam 1990; 24(1):46-53.

2. Sharma HK. Drugs and substance abuse problems, interdisciplinary studies of causes, consequences and preventions, In: Paul Mc, editor New Delhi (IN); Mittal Publication 2005:193-208.

3. www.dhakatribune.com/crime/2013may/27/six-million-spend-tk700rsdrugs-every-day.

4. Lucy HR, Flora SM. Sociodemographic characteristics of the drug addicts, five years data. JOPSOM 2002; 22(1):60-8.

5. Gupta VK, Kaur P, Singh G et al. A study of profile of patients admitted in the drug de-addiction centres in the state of Punjab. International Journal of Research in Health Sciences 2013; 1(2):53-61.

6. Mohan C, Dhar V, Lal B. A study of 1 dedication clinic at GMC (Psychiatric hospital) Jammu (J \& K). Indian J Psychiatry abstract supplement 2004; 34:23.

7. Singh B, Singh V, Vij A. Sociodemographic profile of substance abusers attending a deaddiction centre in Ghaziabad. Ind Medico 2006; 6(1):1-3.

8. De Silva \& Foneska P. Drug addicts and their behavior related to drug addiction among the institutionalized addicts of Galle district, Galle Medical Journal 2008; 13(1):9-13.

9. Hossain KJ, Fariduzzaman M, Kamal MM et al. Drug addiction and Bangladesh, Sociodemographic family profile. JOPSOM 2007; 26(1):56-70.

10. Venkatesan J, Stelina; Substance dependence- Decarles apart in teaching hospital. Indian J Psychiatry 2008; 50:100-5.

11. Islam SKN, Hossain K, Ahsan M. Sexual life style drug habit and sociodemographic status of drug addicts in Bangladesh. Public Health volume 2005; 114(5):389-92.

12. Kadri AM, Bhagyalaxmi A, Kedia G. A study of socio-demographic profile of substance abusers attending a de-addiction centre in Ahmedabad city. Indian J Community Med 2003; 28:74-6.

13. Ray R. National Drug Dependence. Treatment centre. AllMS. New Delhi (IN): WHO Biennium Project:2006-2007. 